\title{
Unlicensed Driving Among California High School Seniors
}

\author{
Katherine E. Heck ${ }^{1}$, Carla Sousa ${ }^{2}$, Christian L. Hanna ${ }^{3}$, and Keith Nathaniel ${ }^{2}$ \\ ${ }^{1}$ 4-H Center for Youth Development, UC Davis, ${ }^{2}$ UC Cooperative Extension, \\ and ${ }^{3}$ Michigan Public Health Institute
}

\begin{abstract}
The driving behaviors and characteristics of unlicensed teenage drivers have been little explored. For this study of behaviors of unlicensed California teen drivers, 2,144 high school seniors at 13 school sites in California completed a written survey. Unlicensed driving was ascertained by combining survey questions about licensing and driving. Data were analyzed to examine characteristics of unlicensed drivers compared with licensed drivers, and to examine risk behaviors among the unlicensed drivers. A total of 12.4 percent $(n=265)$ of students reported driving a motor vehicle without a driver's license or permit, while two-thirds of surveyed students had either a license or a permit, and the remainder did not drive. Unlicensed drivers were primarily male (56 percent) and Latino (67 percent); unlicensed drivers were more likely than others to attend a school with a lower-income population. Licensed and unlicensed drivers reported similar rates of driving after alcohol or other drug use. Licensed drivers were more likely than unlicensed drivers to report having been in a crash, but this difference was no longer significant after adjustment for risk behaviors. Unlicensed driving was fairly common in this sample, but did not appear to represent an excess risk relative to licensed drivers.
\end{abstract}

(C) 2008 Californian Journal of Health Promotion. All rights reserved.

Keywords: adolescent, driving, unlicensed, California, socioeconomic factors

\section{Introduction}

Unlicensed drivers in the U.S. and other countries constitute a substantial fraction of drivers and of crashes (DeYoung, Peck, \& Helander, 1997; Griffin \& DeLaZerda, 2000; Lam, 2003; Silcock, Sunter, \& van Lottum, 1999). One-fifth of fatal crashes in the United States involve a driver with no license or a revoked license (AAA Foundation for Traffic Safety, 2008). Unlicensed drivers are not all alike; they fall into several categories. Some have never been licensed, some are not eligible to receive a license because they are too young or are not in the United States legally, and others have had their driving privileges suspended or revoked (Scopatz, Hatch, DeLucia, \& Tays, 2003).

Multiple factors contribute to the decision of young people to drive unlicensed, but the factors leading to and the circumstances surrounding unlicensed driving have been sparsely investigated. Some possible reasons for adolescents to drive without a license could include being under the legal licensing age, but needing or wanting to drive anyways; financial barriers to licensing and insurance; lack of time or motivation to obtain a license; legal reasons, such as being an undocumented immigrant or having had one's license revoked; logistical considerations, such as not having regular access to a vehicle, and thus not feeling the effort or costs of licensing are worthwhile; or simply not recognizing or believing that a driver's license is an important precondition to driving.

The number or proportion of unlicensed drivers is difficult to estimate, as is the total driving exposure of unlicensed drivers, since their status is unknown to law enforcement until they are cited or have a crash (DeYoung et al., 1997). Studies of the prevalence and characteristics of unlicensed drivers are limited, although 
unlicensed drivers are at increased risk of injury compared with other drivers (Blows, Ivers, Connor, Ameratunga, Woodward, \& Norton, 2006). A national study indicated that about 20 percent of all fatal crashes involved a driver who did not have a valid license at the time of the crash (Scopatz et al., 2003). Among the unlicensed drivers in those crashes, about twothirds had a suspended, revoked, or expired license while a third were never licensed.

In California, 21 percent of all fatal crashes involved an unlicensed driver. Compared with other large states, California has a disproportionate share of fatal crashes involving unlicensed drivers (Griffin \& DeLaZerda, 2000). An examination of fatal crash data for California from 1987-1992 showed that among two-vehicle crashes, almost 12 percent of the drivers found to be at fault had no license, and an additional 24 percent had a suspended or revoked license (DeYoung et al., 1997). According to 2005-07 data from the Fatal Accident Reporting System (FARS), about 18 percent of California drivers ages 10-17 who were involved in fatal crashes had no license, while about 6 percent had an invalid license (one that had been revoked, canceled, denied, or expired) (U.S. Department of Transportation).

Unlicensed driving among young people has been less studied than among the population at large. Studies suggest 1 in 9 young drivers involved in a fatal crash are unlicensed (Hanna, Taylor, Sheppard, \& Laflamme, 2006). Drivers who are below driving age, and therefore "prelicensure," constitute a substantial number of those involved in crash fatalities. However, crashes involving under-age drivers occur predominantly in states that allow driving at age 14 (Frisch \& Plessinger, 2007). The few selfreported surveys that have been published focusing on unlicensed teenage driving indicate that the frequency of unlicensed driving may vary by region. Two regional studies from the United States found reported unlicensed driving ranging from 14 percent to 58 percent of the young people surveyed (Ferguson, Leaf, Williams, \& Preusser, 1996; Williams, Lund, \& Preusser, 1985). A nationally representative survey of 9th-11th graders on driving done in
2006 found that 4.2 percent reported at least some unlicensed driving; unlicensed driving was more commonly reported among black or Hispanic students than among white students (Elliott, Ginsburg, \& Winston, 2008).

Studies from the United States report unlicensed driving to be more common among males and among drivers closer to the age of licensing than among younger teens. International comparisons suggest similar results (Lam, 2003; Harré, Field, \& Kirkwood, 1996; Harré, Brandt, \& Dawe, 2000; Bina, Graziano, \& Bonino, 2006). However, few self-reported studies in recent years have examined the prevalence or characteristics of unlicensed driving among a diverse socioeconomic and ethnic population. It is important to understand more about the behaviors and frequency of young unlicensed drivers as they may pose a threat to road traffic safety; in addition a greater understanding of unlicensed drivers could be used to promote licensure among those who are unlicensed.

\section{California licensure laws}

A review of driving and licensure laws specific to California is important when examining unlicensed driving among adolescents. In California, graduated driver licensing laws allow youth who have taken driver education and have completed or are currently taking driver training (the in-car training that follows driver education) to receive a driving permit at age $151 / 2$, which allows them to drive under the supervision of an adult who is age 25 or older. Driver education and training are often completed privately in California, sometimes in separate courses. Driver training is almost completely absent from public schools, and many do not offer driver education either. At age 16, after passing the DMV's written and driving tests, students may receive a driver's license, but for the next 12 months they cannot drive between 11 p.m. and 5 a.m., and cannot carry passengers under age 20 .

For this study, we refer to adolescents who drive but have no license or permit as "unlicensed drivers." It is possible that some adolescents in this study who report having no license may have previously had one, but had it revoked due to driving under the influence or another 
violation; however, it is likely that most unlicensed drivers in this study are "prelicensure," rather than having a license revoked or denied. These "pre-licensed" students do not have a license or permit either because they are not authorized to receive one (if they are not in the United States legally), or because, for a variety of possible reasons, they have not yet obtained one. The purposes of this descriptive study were to examine the prevalence of reported unlicensed driving among a sample of high school seniors in California and to compare behaviors and characteristics of unlicensed and licensed students.

\section{Methods}

\section{Study design}

This study included 2,144 senior class students attending thirteen California high schools. The schools in the study included twelve public high schools and one private parochial high school, with senior class sizes ranging from 70 to over 400 students. The schools, which represent a convenience sample of schools agreeing to participate, and not a random or representative sample of schools, cover a large geographic area (seven counties in California) representing a range of population densities, ethnic diversity, and income levels. The focus group and the survey research were approved by the University of California-Davis Human Subjects Review Board.

In order to provide information about the driving context, schools were categorized as being rural (located in a town or Census Designated Place of fewer than 10,000 population), suburban/town (schools in areas with a population of 10,000 to 74,999 ), or urban (located in cities of 75,000 or more). Overall, 19 percent of the students attended high schools in rural areas (five schools), 49 percent attended high schools in suburbs or towns (four schools), and 32 percent attended urban high schools (four schools).

Schools were also classified as higher, moderate, or lower income based on the proportion of students who received free or reduced-price meals at the school (data drawn from California Department of Education, 2008). Three schools were classified as higher-income schools $(<20$ percent receiving free or reduced-price meals); six schools were classified as moderate-income (between 20 and 49 percent); and the remaining four schools are low income (at least 50 percent of students received free or reduced-price meals). One-third of students in the study attended higher-income schools; 40 percent were in moderate-income schools, and 26 percent were in lower-income schools.

\section{Survey instrument and administration}

The questionnaire was designed to learn more about the circumstances of teen driving, concerns teens had about driving and driver education, and the role of families in teen driver education and training. To learn more about teen opinions about driving, prior to survey design and administration, focus groups were conducted with 48 youth in six focus groups in two of the Central Valley schools.

A four-page in-class paper survey on driving was administered to high school seniors in 2006. The survey included 31 questions on topics related to driving behaviors that included licensure status, driver education and training, driving experiences, as well as demographics. Some of the questions were multiple-choice while others were open-ended. Teachers at each school in cooperation with the research team administered surveys to students in English or Spanish, as needed by the student; the vast majority of surveys were taken in English. Prior to survey administration a note was sent home to parents in English and Spanish, and in some schools, Hmong and/or Russian, as requested by the school, for passive parental consent. Twelve parents requested that their child not take the survey, so these students were excluded. Among seniors in each school on the day of the survey, response rates exceeded 95 percent. The overall response rate was 68 percent of all enrolled seniors at the schools because of absences on the day of survey administration.

\section{Measures}

Unlicensed driving was determined by combining questions about licensure status with questions about driving experiences. Respondents were asked whether they have a license, a permit, or neither. Later questions 
asked about their experiences with driving, including where they drive (to school; to work; to run errands or help with family responsibilities; to go to clubs, sports practice or other activities; to go out with friends) and an open-ended question about how many hours per week they drive. Students who reported in the first question that they had neither a license nor permit and who reported in a later question that they drove (reporting places that they drove, or reporting driving more than zero hours per week) were classified as unlicensed drivers. Students were otherwise classified as having a permit or license, or for those without a license or permit and who did not report driving, as nondrivers.

In addition to the above questions, students who reported driving were asked about driving experiences and behaviors. These questions included reasons why they did not have a license if they did not (with categories including having no car; it's too expensive; licensing being too much trouble; GDL rules being too restrictive; not being allowed by parents or the state; don't want to; it's better not to have a license if you have an accident or get a ticket; other); the length of time the respondent had been driving (<6 months, 6-11 months, or $>12$ months); the most helpful resource when learning to drive (driver's education class, driver training, parents, other relatives, friends, or other); parental rules and responsibilities set about driving (paying for their own insurance, gas, or car; being required to maintain the car; having to run errands; having a curfew; having to drive others places; having to keep grades up; not being allowed to drive with friends in the car); frequency of following rules of the road (always, usually, sometimes or rarely); night driving (does the respondent drive after 11:00 p.m.); whether the respondent drives with friends in the car; whether the respondent has driven after alcohol use or drug use; and whether the respondent has been in a crash. Students were also asked demographic information including age, gender, and race/ethnicity (categorized as Latino, non-Hispanic white, Asian/Pacific Islander, African American, or Native American). All items were self-reported and were asked only in this cross-sectional survey, so reliability of the survey items was not measurable.

\section{Data analysis}

Data were entered in Excel and recoded using SAS (SAS Institute Inc., 2004). Open-ended responses were coded to categories during the data entry and analysis process. Multivariate logistic regression analysis was used to examine whether licensure status of drivers was a significant predictor of having had a crash. Final analyses, including crosstabs and logistic regression analyses, were completed using SUDAAN (Research Triangle Institute, 2001) to adjust for the nested cluster sampling frame of the survey. Because students were sampled as a result of attending a particular school, their results may have been clustered according to the schools they attended. Treating a cluster sample design in analysis as though it were a simple random sample has the potential to create erroneous results. SUDAAN adjusts for the cluster sample method to provide the correct standard errors. The school was used as the clustering variable for these analyses.

\section{Results}

Table 1 shows several characteristics of students with a license or permit, unlicensed drivers, and non-drivers. The overall sample was 34 percent Latino, 42 percent non-Hispanic white, 12 percent Asian/Pacific Islander, 6 percent African American and 3 percent Native American. This was fairly similar to the ethnic distribution of the California high school senior population at the time, which was comprised of 39 percent Latino students, 37 percent non-Hispanic white, 13 percent Asian/Pacific Islander, 8 percent African American and 1 percent Native American (California Department of Education, 2008).

Approximately 12 percent of respondents were classified as unlicensed drivers, 54 percent had a license, 11 percent had a permit, and 22 percent did not drive. (Comparisons reported here for tables 1-4, along with p-values, were calculated using Proc Crosstab in SUDAAN, except for means which were calculated using SAS). Unlicensed driving was more frequently 
Table 1. Demographic characteristics of by licensure status

\begin{tabular}{|c|c|c|c|c|c|}
\hline & $\begin{array}{c}\text { Student has } \\
\text { license }\end{array}$ & $\begin{array}{c}\text { Student has } \\
\text { permit }\end{array}$ & $\begin{array}{c}\text { Drives, no } \\
\text { license or } \\
\text { permit }\end{array}$ & $\begin{array}{l}\text { Does not } \\
\text { drive }\end{array}$ & $\begin{array}{l}\text { P-value for } \\
\text { difference } \\
\text { across } \\
\text { groups }\end{array}$ \\
\hline & $(n=1,159)$ & $(n=240)$ & $(n=265)$ & $(n=480)$ & \\
\hline \multicolumn{6}{|l|}{ Race/ethnicity } \\
\hline Hispanic/Latino & $37.1 *$ & 13.5 & 21.3 & 28.2 & \\
\hline $\begin{array}{l}\text { Non-Hispanic } \\
\text { White }\end{array}$ & 78.5 & 7.0 & 2.7 & 11.8 & \\
\hline $\begin{array}{l}\text { Asian/Pacific } \\
\text { Islander }\end{array}$ & 46.3 & 13.7 & 9.3 & 30.8 & \\
\hline African American & 29.5 & 16.1 & 25.9 & 28.6 & \\
\hline Native American & 59.6 & 11.5 & 9.6 & 19.2 & $<.0001$ \\
\hline Male & 57.3 & 11.1 & 14.5 & 17.1 & \\
\hline Female & 54.4 & 11.3 & 9.8 & 24.6 & $<.0001$ \\
\hline Rural & 50.5 & 15.5 & 17.0 & 17.0 & \\
\hline Suburb or town & 63.7 & 9.6 & 5.7 & 21.0 & \\
\hline Urban & 54.0 & 11.2 & 12.4 & 22.4 & $<.0001$ \\
\hline $\begin{array}{l}\text { Higher-income } \\
\text { school }\end{array}$ & 82.5 & 7.4 & 1.3 & 8.9 & \\
\hline $\begin{array}{l}\text { Moderate-income } \\
\text { school }\end{array}$ & 52.5 & 11.8 & 9.7 & 26.1 & \\
\hline $\begin{array}{l}\text { Lower-income } \\
\text { school }\end{array}$ & 20.5 & 15.2 & 30.5 & 33.9 & $<.0001$ \\
\hline Mean age & 17.2 & 17.2 & 17.1 & 17.1 & .6539 \\
\hline
\end{tabular}

*Values are percentages.

reported among male respondents (15 percent of male students reported driving without a license, compared with 10 percent of female students); Latino students (21 percent driving unlicensed); and African American students (26 percent driving unlicensed). Unlicensed driving was most commonly reported by students at rural schools (17 percent of rural students) and least commonly by students in suburbs or towns (6 percent). Reports of unlicensed driving varied dramatically by income level of students at the schools. At higher-income schools, over 82 percent of students reported that they had a driver's license and just 1 percent were driving unlicensed. This contrasted sharply with students at lower-income schools, where only about 21 percent of students had a license, and 31 percent were driving without a license. Age was the only demographic variable that did not differ significantly across the four groups.

Both unlicensed drivers and non-drivers reported many reasons for not having a license, shown in Table 2. These results were drawn from categorical options as well as coded "other" text responses to this question. Having no car, costs associated with driving or licensing, and not being allowed to drive by parents or the state 
Table 2. Reasons unlicensed drivers and non-drivers reported for non-licensure

\begin{tabular}{|c|c|c|c|}
\hline & $\begin{array}{l}\text { Unlicensed } \\
\text { drivers }\end{array}$ & $\begin{array}{c}\text { Non- } \\
\text { drivers }\end{array}$ & $\begin{array}{c}\text { P-value } \\
\text { for } \\
\text { difference }\end{array}$ \\
\hline Reason & $(n=265)$ & $(n=462)$ & \\
\hline $\begin{array}{l}\text { There is no car I can } \\
\text { use }\end{array}$ & $12.8^{*}$ & $14.5^{*}$ & .5307 \\
\hline It's too expensive & 11.7 & 14.1 & .3637 \\
\hline $\begin{array}{l}\text { I'm not allowed (my } \\
\text { parents or the state } \\
\text { won't let me) }\end{array}$ & 9.4 & 8.9 & .8006 \\
\hline $\begin{array}{l}\text { Waiting until I turn } 18 \\
\S\end{array}$ & 8.7 & 8.2 & .8318 \\
\hline I haven't had time $\S$ & 7.9 & 5.0 & .1091 \\
\hline I just don't want to & 7.6 & 12.1 & .0525 \\
\hline It's too much trouble & 6.4 & 5.4 & .5769 \\
\hline $\begin{array}{l}\text { The driving laws for } \\
\text { teenagers are too } \\
\text { restrictive }\end{array}$ & 6.0 & 4.6 & .3786 \\
\hline $\begin{array}{l}\text { It's in process } \\
\text { (I'm working on } \\
\text { getting it now) } \S\end{array}$ & 5.3 & 3.9 & .3806 \\
\hline I'm undocumented $\S$ & 3.4 & 0.9 & .0133 \\
\hline I'm too lazy $\S$ & 2.3 & 3.7 & .2943 \\
\hline $\begin{array}{l}\text { It's better not to have a } \\
\text { license if you get a } \\
\text { ticket }\end{array}$ & 0.8 & 0.2 & .2762 \\
\hline I'm afraid $\S$ & 0.4 & 2.6 & .0298 \\
\hline Other reasons & 14.7 & 13.0 & .5130 \\
\hline
\end{tabular}

*Values in this column are percentages.

$\S$ Text response.

were the most frequent responses. Many students also reported that they were waiting until they turn age 18 to obtain a license, which they had not yet had time to obtain a license, or that they were in the process of obtaining one. Non-drivers were significantly more likely than unlicensed drivers to report having no interest in obtaining a license and were less likely to report undocumented immigration status as a factor in their licensure.

Table 3 describes selected aspects of the context of driving by licensure status. Regardless of license status, most students reported that their parents were the greatest resource for them in learning to drive. However, unlicensed drivers were far less likely than students with permits or licenses to report driver training as an important resource (only 6 percent, vs. 31 percent for licensed drivers). Reasons students reported for driving also varied by licensure status. Unlicensed drivers and students with a permit were significantly more likely to report driving to run errands or help with family responsibilities, whereas licensed drivers were more likely to report driving to school, work, clubs, sports practice or other activities, or to go out with friends. When asked about parental rules and restrictions regarding their driving, unlicensed drivers reported the fewest on average while licensed drivers had the most.

Licensure status was associated with reported experiences with driving, shown in Table 4. Licensed drivers reported having driven for a significantly longer period of time than respondents with permits or unlicensed respondents, with 62 percent driving for over a year compared with 41 percent of unlicensed drivers and just 17 percent of those with a permit. Students who were licensed drove the highest number of hours per week, while students with a permit reported the fewest hours per week of driving. Unlicensed drivers were less likely than other drivers to report that they regularly drive with friends in the car or that they drive after 11:00 pm (the hour specified in California's graduated driver licensing system). Licensed drivers were more likely than either students with permits or unlicensed drivers to report having been distracted by someone else in the car while driving. Licensed drivers were significantly more likely than unlicensed drivers to report having been in a crash. Drivers who had been in a crash reported significantly more hours of driving per week than students who had not been in a crash (11.4 hours per week for students who had been in a crash, compared with 9.0 hours per week for students who had not been in a crash); this disparity held true for both licensed and unlicensed drivers.

A logistic regression model was created to examine whether driving unlicensed was a predictor of reporting having had a crash. Since so many of the unlicensed drivers were Latino 
and responses may vary between these students and others, interaction terms with Latino ethnicity were tested but were not found to be statistically significant (for the full model, $\mathrm{p}=$ .6182 for Latino*unlicensed, and $p=.1677$ for
Latino*driver's permit). Stratified models by race also showed essentially the same results, so results presented are for all students aggregated. In bivariate models, students who were

Table 3. Percentage of driving context by licensure status

\begin{tabular}{|l|c|c|c|c|}
\hline & $\begin{array}{c}\text { Student has } \\
\text { license }\end{array}$ & $\begin{array}{c}\text { Student has } \\
\text { permit }\end{array}$ & $\begin{array}{c}\text { Drives, no } \\
\text { license or } \\
\text { permit }\end{array}$ & $\begin{array}{c}\text { p-value for } \\
\text { difference }\end{array}$ \\
\hline $\begin{array}{l}\text { Main resource when } \\
\text { learning to drive }\end{array}$ & $(\mathrm{n}=1,159)$ & $(\mathrm{n}=240)$ & & \\
\hline Driver education & $9.6^{*}$ & 13.3 & 13.5 & $<.0001$ \\
\hline Driver training & 30.8 & 24.8 & 6.0 & \\
\hline Parents & 45.8 & 49.5 & 52.4 & \\
\hline Other relatives & 2.8 & 6.2 & 12.7 & \\
\hline Friends & 3.3 & 3.8 & 8.7 & \\
\hline Other & 7.7 & 2.4 & 6.8 & \\
\hline & & & & \\
\hline $\begin{array}{l}\text { Mean number of reported } \\
\text { parental rules about driving }\end{array}$ & 3.2 & 2.9 & & $<.0001$ \\
\hline & & & & \\
\hline Main reasons to drive & & & & \\
\hline Get to school & 84.7 & 52.7 & 45.8 & $<.0001$ \\
\hline Get to work & 43.3 & 30.8 & 31.2 & $<.0001$ \\
\hline $\begin{array}{l}\text { Run errands, help with } \\
\text { family responsibilities }\end{array}$ & 33.8 & 51.4 & 45.4 & $<.0001$ \\
\hline $\begin{array}{c}\text { Go to clubs, sports } \\
\text { practice, other activities }\end{array}$ & 37.8 & 21.2 & 18.1 & $<.0001$ \\
\hline \begin{tabular}{l} 
Go out with friends \\
\hline
\end{tabular} & 46.0 & 30.3 & 29.6 & $<.0001$ \\
\hline
\end{tabular}

$*$ Values are percentages.

unlicensed were significantly less likely to report a crash than students with a driver's license $(\mathrm{OR}=0.5 ; 95 \%$ confidence interval $=$ $0.3-0.8$ ), as were students with a permit relative to those with a license. However, after adjusting for demographics (race, ethnicity, sex, attended an urban school, attended a low-income school) and driving experiences (reported drinking and driving, was distracted by a passenger, drove after 11:00 pm, had been driving for 12 months or more, or average hours per week driven), licensure status was no longer a statistically significant predictor of having had a crash.
Table 5 shows the fully adjusted model. Having driven after drinking alcohol and driving after 11:00 p.m. were statistically significant predictors of having had a crash. None of the demographic factors was significant.

\section{Discussion}

This study presents new information on the frequency of driving without a license or permit among multiple ethnic and income groups in the sample and on the driving experiences for young unlicensed drivers. Many high school seniors in 
this sample drove without having a license. The prevalence of unlicensed driving reported among this sample of California youth was similar to previously reported results for the prevalence of unlicensed driving using crash fatality data in the United States and in Australia (Griffin \& DeLaZerda, 2000; Blows et al., 2006; Hanna et al., 2006). The results of these self-reported data are somewhat higher than the results reported in a recent national study (Elliott et al., 2008); however that survey was of younger students than this one, so these results could be consistent with an increase in unlicensed driving as youth age. Crash-fatality data from FARS would suggest that the frequency of unlicensed driving among teenage drivers in California fatal crashes is higher than the 12 percent found here (U.S. Department of Transportation, 2009). This survey sampled only 12th graders enrolled in school in 2006. It is possible that youth who have dropped out of school have higher rates of unlicensed driving than those who continue in school, which could explain the disparity between self - reported unlicensed driving and the higher numbers in crash-fatality data.

Having a driver's license, and thus the ability to drive, has represented freedom for many American young people, as well as being a convenience for parents who may less often need to drive their teenagers. Why would high school seniors fail to obtain a permit or a license? This study found that socioeconomic circumstances appeared to play a role in unlicensed driving for many students. Unlicensed students in this study were significantly more likely than licensed ones to attend schools where a high proportion of students received free- or reduced-price meals.

In addition to school demographic differences between licensed and unlicensed students, suggesting that finances might be a reason for being unlicensed, direct reports from the respondents indicated that costs were a barrier for some students to obtaining a license. Many unlicensed drivers, as well as many non-drivers, reported that they were unable to afford the costs associated with obtaining a license, which include the cost of driver education and driver training, the cost of the license itself, automotive insurance, the cost of gas and maintenance, and in some cases, the cost of a car, if parents do not or cannot provide one for the student's use. Although hands-on experience is critical when learning to drive, the high cost of private driver training may systematically exclude some young people from licensing.

Unlicensed students are likely to have not taken driver training, and thus are on the roads without the basic experiential learning the state requires for novice young drivers. Almost no public schools in California offer driver training, and many do not offer driver education either, particularly those in rural areas or with fewer resources available to hire credentialed driver education instructors. Thus, students who can least afford private driver education may be those who are also least likely to have access to it via their high schools, in addition to being those who may most need to drive given the family responsibilities they reported in this survey. Reinstatement of professional driving education in public schools or subsidies for student drivers who cannot afford the costs of driver education and training could help mitigate the apparent need of low-income youth to drive unlicensed.

Undocumented immigration also may have contributed to driving without a license for some of the unlicensed drivers in this study. Most unlicensed drivers in this study were Latino, and a number of them indicated that they were undocumented immigrants, and thus cannot legally obtain a driver's license in California. California's approximately 2.4 million undocumented residents come predominantly from Mexico and a substantial fraction of these immigrants are teenagers (Passel, 2005). Although undocumented status was not asked directly, 9 percent of unlicensed drivers said the main reason they did not have a license was that they were not allowed by parents or the state to obtain one, and an additional 3 percent of unlicensed drivers and 1 percent of non-drivers volunteered in text responses that they were undocumented. The relatively high prevalence of unlicensed driving among both youth and adults in California may be one unintended consequence of the immigration laws. However, 
undocumented immigration was not entirely responsible for unlicensed driving; there were members of all ethnic groups and socioeconomic circumstances who reported unlicensed driving in this survey.

Some research suggests graduated driver licensing laws may have contributed to unlicensed driving and thus increases in crash fatalities among unlicensed 16- and 17-year-olds in California (Males, 2007). Several respondents in this survey stated that they were waiting until age 18 to become licensed, but some of those students drove anyways. In this survey, 61 students (8.3 percent of all unlicensed students) reported in text responses that they had not obtained a license because they were "waiting until I turn 18." At age 18, graduated driver licensing laws would no longer apply to them, and many insurance companies require motor vehicle insurance upon the 18th birthday regardless of whether the youth has a license or not. Thus, at age 18, insurance costs and graduated licensing laws may no longer be incentives to avoid obtaining a license. Despite the barriers of cost and driving restrictions, students in their late teens may still need to drive for a variety of reasons. The tightening of driving laws for 16- and 17-year-olds has the potential in some cases to increase the risk of unlicensed driving among teenagers.

Do adolescents who drive without a license constitute a significant public health risk? Results from this survey indicated that students who drove without a license did not report more crashes than did students who drove with a license. It is possible that unlicensed drivers drove less frequently or with greater care, reducing their exposure and risk, but exact levels of exposure and risk behaviors were not possible to determine accurately from these data (although the hours per week they reported driving was higher for licensed than for unlicensed students). Given their relatively young age, as well as the responses they made in the question about why they have no license, most students in this study who drove unlicensed were likely "pre-licensure," rather than driving after having a license revoked. The elevated risk of fatal crash injury among unlicensed drivers may be due primarily to the prevalence of crashes among adult drivers who have revoked licenses. However, as described earlier, among young drivers, FARS data indicate that unlicensed drivers constitute a substantial proportion of fatal crashes (U.S. Department of Transportation, 2009); it is possible that the risk among unlicensed teen drivers who are not enrolled in school, and thus not captured in this study, exceeds the risk among those who are enrolled in school. In addition, unlicensed drivers almost certainly have no insurance, and thus no ability to pay for damage they may cause. The State Department of Motor Vehicles and insurers do not receive funds from these drivers. Pre-licensed drivers have not demonstrated that they know the rules of the road and can drive safely, and may be less likely to comply with these laws since they are under no threat of license revocation, "points" on their license, or increased insurance premiums as are licensed drivers.

\section{Strengths and limitations}

A strength of this study is that it provides selfreported data on unlicensed driving for a diverse sample of high school seniors from a large geographic area of California. However, despite the ethnic similarity to California's population as a whole, this study cannot be taken to represent all California high school seniors. The study sample of 13 schools is unweighted, and results are limited to these students. There is the possibility of Type 1 error based on the large sample size and the nonrandom sampling of schools; in other words, statistically significant differences observed here could be due to chance rather than to a true underlying difference.

This survey does not include high school dropouts and students who were absent on the day of survey administration. Students who have dropped out of school have been demonstrated to have higher levels of a variety of risk behaviors (e.g., Kogan, Luo, Brody, \& Murry, 2005; Townsend, Flisher, \& King, 2007); it is possible that the prevalence of unlicensed driving, and other high-risk driving behaviors examined in this study such as driving after alcohol use, would be higher in a sample that 
included dropouts. The survey was not designed specifically to capture fully the experiences of unlicensed drivers, and thus unlicensed driving data available here are limited by the questions asked. Driving experiences and frequencies reported in this study are limited by the ability to accurately gauge driving exposure; it was not possible with these data to accurately determine the amount of time students spent behind the wheel and thus to compare true rates of events. Finally, any study using self-reported data is limited by the willingness or ability of subjects to recall accurately and respond honestly to questions. It is possible that illegal behaviors such as driving unlicensed, driving after drinking alcohol, or other less socially acceptable behaviors may have been underreported in this study.

\section{Conclusions}

Many high school seniors in this sample drove a motor vehicle and engaged in behaviors known to increase the risk of road traffic injury, despite having neither a license nor permit. Unlicensed drivers reported a somewhat lower occurrence of crashes, although this difference was not statistically significant after adjustment for reported driving behaviors. These data suggest that unlicensed and licensed drivers have differing driving patterns, purposes, and precautions when operating a motor vehicle. Further research could investigate the frequency over time of unlicensed driving, reasons for unlicensed driving specifically, and further details about barriers to youth obtaining a license to drive legally.

\section{References}

AAA Foundation for Traffic Safety (2008). Unlicensed to Kill: Research Update. Washington, DC : AAA Foundation.

Bina, M., Graziano, F., \& Bonino, S. (2006). Risky driving and lifestyles in adolescence. Accident Analysis and Prevention, 38, 472-481.

Blows, S., Ivers, R.Q., Connor, J., Ameratunga, S., Woodward, M., \& Norton, R. (2006). Unlicensed drivers and car crash injury. Traffic Injury Prevention, 6, 230-234.

California Department of Education (2008). Ed-Data: School reports. Available at http://www.eddata.k12.ca.us/ .

DeYoung, D.J., Peck, R.C., \& Helander, C.J. (1997). Estimating the exposure and fatal crash rates of suspended/revoked and unlicensed drivers in California. Accident Analysis and Prevention, 29, $17-23$.

Elliott, M.R., Ginsburg, K.R., \& Winston, F.K. (2008). Unlicensed teenaged drivers: Who are they, and how do they behave when they are behind the wheel? Pediatrics, 122, e994-e1000.

Ferguson, S.A., Leaf, W.A., Williams, A.F., \& Preusser, D.F. (1996). Differences in young driver crash involvement in states with varying licensure practices. Accident Analysis and Prevention, 28, 171-180.

Frisch, L., \& Plessinger, A. (2007). Fatal passenger vehicle crashes with at least 1 driver younger than 15 years: A Fatality Analysis Reporting System study. Journal of Rural Health, 23, 158-162.

Griffin, L.I., \& DeLaZerda, S. (2000). Unlicensed to kill. Washington, DC: AAA Foundation for Traffic Safety.

Hanna, C.L., Taylor, D.M., Sheppard, M.A., \& Laflamme, L. (2006). Fatal crashes involving unlicensed drivers in the US. Journal of Safety Research, 37, 385-393.

Harré, N., Brandt, T., \& Dawe, M. (2000). The development of risky driving in adolescence. Journal of Safety Research, 31, 185-194.

Harré, N., Field, J., \& Kirkwood, B. (1996). Gender differences and areas of common concern in the driving behaviors and attitudes of adolescents. Journal of Safety Research, 27, 163-173.

Kogan, S.M., Luo, Z., Brody, G.H., \& Murry, V.M. (2005). The influence of high school dropout on substance use among African-American youth. Journal of Ethnicity in Substance Abuse, 4, 3551. 
Lam, L.T. (2003). A neglected risky behavior among children and adolescents: Underage driving and injury in New South Wales, Australia. Journal of Safety Research, 34, 315-320.

Males, M. (2007). California's graduated driver license law: Effect on teenage drivers' deaths through 2005. Journal of Safety Research, 38, 651-659.

Passel, J.S. (2005). Estimates of the size and characteristics of the undocumented population. Pew Hispanic Center, Washington, D.C.

Research Triangle Institute (2001). SUDAAN User's Manual (Release 8.0). Research Triangle Park, NC: Research Triangle Institute.

SAS Institute, Inc. (2004). SAS 9.1.3 Help and Documentation. Cary, NC: SAS Institute, Inc.

Scopatz, R.A., Hatch, C.E., DeLucia, B.H., \& Tays, K.A. (2003). Unlicensed to kill: The Sequel. Washington, DC: AAA Foundation for Traffic Safety.

Silcock, D., Sunter, A., \& van Lottum, C. (1999). Unlicensed driving: A scoping study to identify potential areas for further research. Cheadle, UK: AA Foundation for Road Safety Research.

Townsend, L., Flisher, A.J., \& King, G. (2007). A systematic review of the relationship between high school dropout and substance use. Clinical Child and Family Psychology Review, 10, 295-317.

U.S. Department of Transportation. FARS Query System. http://www.fars.nhtsa.dot.gov/Query Tool/QuerySection/SelectYear.aspx. Accessed January 29, 2009.

Williams, A.F., Lund, A.K., \& Preusser, D.F. (1985). Driving behavior of licensed and unlicensed teenagers. Journal of Public Health Policy, 6, 379-393.

Author Information

Katherine E. Heck, MPH*

Department of Human and Community Development

4-H Center for Youth Development

University of California, Davis

1 Shields Ave.

Davis, CA 95616

Phone: (530)754-8755

Fax: (530)754-8440

Email: keheck@ucdavis.edu

Carla Sousa, MS

UC Cooperative Extension

Christian L. Hanna, MPH

Michigan Public Health Institute

Keith Nathaniel, EdD

UC Cooperative Extension

* corresponding author 


\section{Appendix A}

Table 4. Reported driving experiences by licensure status

\begin{tabular}{|c|c|c|c|c|}
\hline & $\begin{array}{l}\text { Student has } \\
\text { license }\end{array}$ & $\begin{array}{c}\text { Student has } \\
\text { permit }\end{array}$ & $\begin{array}{c}\text { Drives, no } \\
\text { license or } \\
\text { permit } \\
\end{array}$ & $\begin{array}{l}\text { p-value for } \\
\text { difference }\end{array}$ \\
\hline & $(n=1,159)$ & $(n=240)$ & $(n=265)$ & \\
\hline \multicolumn{5}{|l|}{$\begin{array}{l}\text { How long have you been } \\
\text { driving? }\end{array}$} \\
\hline$<6$ months & $11.9 *$ & 51.2 & 37.2 & $<.0001$ \\
\hline 6-11 months & 26.0 & 31.6 & 21.6 & \\
\hline 12 months or more & 62.1 & 17.2 & 41.2 & \\
\hline Mean hours driven per week & 10.4 & 7.3 & 8.6 & .0034 \\
\hline Drive after $11 \mathrm{pm}$ & 80.0 & 38.9 & 48.6 & $<.0001$ \\
\hline Drive with friends in the car & 90.9 & 59.5 & 74.6 & $<.0001$ \\
\hline $\begin{array}{l}\text { Was distracted by a } \\
\text { passenger }\end{array}$ & 41.7 & 31.2 & 31.0 & .0003 \\
\hline Drove after drinking alcohol & 20.4 & 6.2 & 13.8 & $<.0001$ \\
\hline Drove after using drugs & 16.6 & 7.7 & 13.4 & .0003 \\
\hline Was in a crash as a driver & 24.4 & 11.1 & 14.9 & $<.0001$ \\
\hline
\end{tabular}

*Values are percentages. 


\section{Appendix B}

Table 5. Odds ratios for having had a crash as a driver among all drivers using multivariate logistic regression analysis

\begin{tabular}{|c|c|c|c|c|}
\hline \multirow{2}{*}{$\begin{array}{l}\text { Variable } \\
\text { Driving related variables }\end{array}$} & \multirow[t]{2}{*}{ p-value } & \multirow[t]{2}{*}{ Odds ratio } & \multicolumn{2}{|c|}{$95 \%$ confidence interval } \\
\hline & & & Lower & Upper \\
\hline Unlicensed driver & .0864 & 0.61 & 0.34 & 1.07 \\
\hline Has a permit & .0894 & 0.59 & 0.32 & 1.08 \\
\hline Licensed driver & (ref.) & & & \\
\hline Drove after drinking alcohol & .0383 & 1.46 & 1.02 & 2.09 \\
\hline Passenger distraction & .0522 & 1.33 & 1.00 & 1.77 \\
\hline Drives after $11 \mathrm{pm}$ & .0019 & 1.91 & 1.27 & 2.88 \\
\hline 12 months or more driving & .0675 & 1.34 & 0.98 & 1.85 \\
\hline Average hours per week driven & .1701 & 1.01 & 1.00 & 1.01 \\
\hline Demographics & & & & \\
\hline Male & .0708 & 0.75 & 0.55 & 1.02 \\
\hline Race-ethnicity & .3220 & & & \\
\hline Latino & & 0.74 & 0.51 & 1.08 \\
\hline African American & & 1.13 & 0.56 & 2.30 \\
\hline Asian/Pacific Islander & & 0.97 & 0.58 & 1.61 \\
\hline Native American & & 1.54 & 0.69 & 3.45 \\
\hline Attends an urban school & .3351 & 1.18 & 0.84 & 1.64 \\
\hline Attends a low-income school & .9743 & 1.01 & 0.62 & 1.64 \\
\hline
\end{tabular}

Reference groups are counterparts (licensed driver; did not drive after drinking; was not distracted; does not drive after $11 \mathrm{pm}$; has driven for fewer than 12 months; female; white, non-Hispanic; attends a school in a suburb, town, or city; attends a moderate- or higher-income school). 